\title{
Correction to: Effectiveness of a SCERTS Model-Based Intervention for Children with Autism Spectrum Disorder (ASD) in Hong Kong: A Pilot Study
}

\section{$\mathrm{Lu} \mathrm{Yu}^{1}$ (D) Xiaoqin Zhu ${ }^{1}$}

Published online: 11 December 2018

(c) The Author(s) 2018

\section{Correction to: \\ Journal of Autism and Developmental Disorders (2018) 48:3794-3807 \\ https://doi.org/10.1007/s10803-018-3649-z}

The article Effectiveness of a SCERTS Model-Based Intervention for Children with Autism Spectrum Disorder (ASD) in Hong Kong: A Pilot Study, written by Lu Yu and Xiaoqin Zhu was originally published electronically on the publisher's internet portal (currently SpringerLink) on June 15, 2018 without open access.

With the author(s)' decision to opt for Open Choice the copyright of the article changed on December 1, 2018 to () The Author(s) 2018 and the article is forthwith distributed under the terms of the Creative Commons Attribution 4.0 International License (http://creativecommons.org/licenses/ by/4.0/), which permits use, duplication, adaptation, distribution and reproduction in any medium or format, as long as you give appropriate credit to the original author(s) and the source, provide a link to the Creative Commons license and indicate if changes were made.

The original article can be found online at https://doi.org/10.1007/ s10803-018-3649-z.

\footnotetext{
$\mathrm{Lu} \mathrm{Yu}$

lu.yu@polyu.edu.hk

1 Department of Applied Social Sciences, The Hong Kong Polytechnic University, Hunghom, Hong Kong, People's Republic of China
} 